\title{
How WEIRD are positive psychology interventions? A bibliometric analysis of randomized controlled trials on the science of well-being
}

\section{Tom Hendriks, Meg A Warren, Marijke Schotanus-Dijkstra, Aabidien} Hassankhan, Tobi Graafsma, Ernst Bohlmeijer \& Joop de Jong

To cite this article: Tom Hendriks, Meg A Warren, Marijke Schotanus-Dijkstra, Aabidien Hassankhan, Tobi Graafsma, Ernst Bohlmeijer \& Joop de Jong (2018): How WEIRD are positive psychology interventions? A bibliometric analysis of randomized controlled trials on the science of well-being, The Journal of Positive Psychology, DOI: 10.1080/17439760.2018.1484941

To link to this article: https://doi.org/10.1080/17439760.2018.1484941

+ View supplementary material $\longleftarrow$

曲 Published online: 29 Aug 2018.

Submit your article to this journal 주

山ll Article views: 118

View Crossmark data $\nearrow$ 


\title{
How WEIRD are positive psychology interventions? A bibliometric analysis of randomized controlled trials on the science of well-being
}

\author{
Tom Hendriksa, Meg A Warren ${ }^{b}$, Marijke Schotanus-Dijkstrac, Aabidien Hassankhann, Tobi Graafsma ${ }^{d}$, \\ Ernst Bohlmeijerc and Joop de Jonge
}

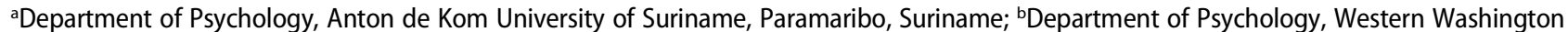
University, Bellingham, WA, USA; 'Department of Psychology, Health and Technology, University of Twente, Centre for eHealth and Wellbeing

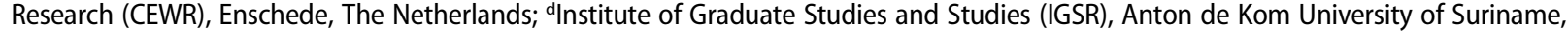

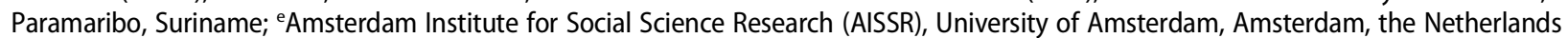

\section{ABSTRACT}

The past two decades have witnessed a rapid rise in well-being research, and a profusion of empirical studies on positive psychology interventions (PPIs). This bibliometric analysis quantifies the extent to which rigorous research on PPIs that employ randomized controlled trials (RCTs) reaches beyond Western Educated Industrialized Rich Democratic (WEIRD) populations. A search was conducted through databases including PubMed, PsycINFO, and Scopus for studies from 1998 to 2017. In total, we found 187 full-text articles that included 188 RCTs from 24 countries. We found that RCTs on the efficacy of PPIs are still predominately conducted in western countries, which accounted for $78.2 \%$ of the studies. All these countries are highly industrialized and democratic, and study populations are often highly educated and have a high income. However, there has been a strong and steady increase in publications from non-Western countries since 2012, indicating a trend towards globalization of positive psychology research.

\section{ARTICLE HISTORY}

Received 16 November 2017

Accepted 15 May 2018

\section{KEYWORDS}

Cross-cultural; intervention; mental health; positive psychology; WEIRD; global mental health equity; bibliometric analysis; treatment gap; RCT randomized controlled trial

\section{Introduction}

Many scholars agree that until recently, research in psychology and other disciplines in the social sciences has been western-centric (Berry, 2013; Cole, 2006; Jahoda, 2016; Stewart, 2012; Sue, 1999). Psychology as a social science has been criticized for being primarily a Western enterprise that uses findings from studies of thought and behavior of people living in the Western hemisphere and generalizes them to the entire human population. On the basis of an analysis of six premier APA journals, Arnett (2008) concluded that American psychologists focus on $5 \%$ to $7 \%$ of the human population. In particular, psychological research is dominated by scholarship emerging from the United States (Eysenck, 2001). Even within cross-cultural psychology, U.S. psychologists are responsible for $50 \%$ to $75 \%$ of all published articles, and tend to be cited more often (Allik, 2013) than psychologists from other countries. Additionally, a large majority of the samples are drawn from undergraduate psychology students at North American universities (Arnett, 2008), and these samples are very atypical and do not represent characteristics of the majority of the world's population. Henrich, Heine, \& Norenzayan (2010a, 2010b) describe these samples as WEIRD - Western, Educated, Industrialized, Rich and
Democratic - to capture the demographic characteristics as well as to allude to the idiosyncratic nature of the populations represented in the majority of published research. The acronym highlights that the larger part of the scientific knowledge about human psychology is based on the findings of studies conducted within a specific research population, namely, wealthy undergraduate students in the U.S.

In line with broader trends in psychological science, as identified by Arnett (2008), a bibliometric analysis of positive psychology publications from the inception of the field in 1998 to 2010 , reported that $74.5 \%$ of the authors were affiliated with institutions in North America, $17.6 \%$ in Europe, 3.2\% in Asia (mostly China), 1.4\% in Africa (mostly South Africa), and $0.9 \%$ in South and Central America. Hence, approximately $94.5 \%$ of the research stems from Western countries, and only $5.5 \%$ from non-Western countries (Schui \& Krampen, 2010). Their analyses included quantitative and qualitative research papers, edited books, book chapters, and dissertations. In this paper, we focus on randomized controlled trials (RCTs) examining the effects of positive psychology interventions (PPIs). PPIs are interventions aimed at increasing positive feelings, behaviors, and cognitions, that use pathways or strategies to 
increase well-being based on positive psychological theories and empirical research (Schueller, Kashdan, \& Parks, 2014; Schueller \& Parks, 2014).

Mirroring the concerns in broader psychological science, cross-cultural psychologists and anthropologists have expressed concern that such a strong North American influence in positive psychology distorts the construction of human happiness and flourishing; positive psychology is bound to North American culture and neglects the cultural embeddedness of positive human behavior (Christopher \& Hickinbottom, 2008; Frawley, 2015). They argue that the positive psychology movement is deeply entrenched in Northern American ideology that emphasizes the pursuit of individual happiness as one of the most important goals in life. The antecedents of human flourishing most frequently studied tend to be those located within the individual. Flourishing is constructed predominately as an individual process and achieved through the cultivation of individual strengths and virtues, while the importance of external factors on macro-and micro-economic levels, as well as social, cultural and even historical factors, are underestimated or simply neglected (Becker \& Marecek, 2008). Thus, the research emerging from North America seems to reflect the foci and cultural values of the region. A more recent systematic review of 863 empirical articles about positive psychology studies published between 1998 to 2014, reported that $41 \%$ of the studies were conducted in the U.S., $24 \%$ in Europe, $7 \%$ in Canada, $6 \%$ in Australia. So, only about $78 \%$ of the articles were conducted in Western countries indicating a trend towards greater global representation of research in positive psychology (Kim, Doiron, Warren, \& Donaldson, 2018). Kim and colleagues' (Kim et al., 2018) review of the research emphases and foci found support for the assertion that the contributions situated outside of North America reflected the values, priorities, and cultural ideologies of the regions in which they originated, and this enriched the science.

Positive psychology is a relative newcomer to the scientific community and still draws some skepticism regarding its credibility (Coyne \& Tennen, 2010; Frawley, 2015; Vazquez, 2013). Since the RCT is considered the gold standard in clinical research - the most rigorous method that can determine causal relations between interventions and outcomes (Sibbald \& Roland, 1998), positive psychology studies that uphold this standard are more likely to be accepted by the broader scientific community. Therefore, we have focused on RCTs of PPIs in this bibliometric review. To summarize, we assess the state-of-the-art with respect to the cultural and socio-demographic context of current RCTs on the effects of PPIs.

\section{Present study}

In this study, we report on the general characteristics of RCTs and present the types of positive activities that are included in the intervention. Further, to address past concerns about positive psychology being too Westerncentric (Cameron, 2016; Christopher \& Hickinbottom, 2008), the current study examines whether positive psychology is truly a 'WEIRD' science, by analyzing the country of origins, educational level of the participants, the industrialization level of the originating countries, the classification of the income levels of these countries, and finally the classification of political regimes.

\section{Method}

\section{Literature search methods}

A systematic literature search was conducted in the following three databases: PubMed, PsycINFO, and Scopus, from 1998 to 2017. The last run was conducted on the 25th of July 2017. The search was conducted by the first and third author. We searched the databases with the following terms: 'positive psycho*' OR wellbeing OR happiness OR happy OR flourishing OR 'life satisfaction' OR 'satisfaction with life' OR optimism OR gratitude OR strengths OR forgiveness OR compassion AND 'random $^{* \prime}$. The search strings were adapted to each database. While Western journals that are devoted to the science of well-being are included in the aforementioned mainstream databases (e.g. the Journal of Positive Psychology and the Journal of Happiness Studies), these databases may not include publications from non-Western positive psychology journals. Therefore, we conducted a search in Google and found two such journals, namely the Indian Journal of Positive Psychology and the Iranian Journal of Positive Psychology. We conducted a hand search through their websites. Finally, reference lists of four recent meta-analyses (Bolier et al., 2013; Chakhssi, Kraiss, SommersSpijkerman, \& Bohlmeijer, 2018; Dickens, 2017; Sin \& Lyubomirsky, 2009) and seven recent review articles on PPIs (Casellas-Grau, Font, \& Vives, 2014; Ghosh \& Deb, 2016; Macaskill, 2016; Rashid, 2015; Sutipan, Intarakamhang, \& Macaskill, 2016; Walsh, Cassidy, \& Priebe, 2017; Woodworth, O'Brien-Malone, Diamond, \& Schuz, 2016) were checked.

\section{Eligibility criteria}

For this study, we focused on RCTs of PPIs. We included: i) randomized controlled trials and clusterrandomized trials on PPIs; ii) studies that were published in peer-reviewed journals; iii) studies published 
from 1998, the inaugural year of positive psychology, to 2017. We excluded: i) non-randomized controlled studies; ii) studies published in dissertations and grey literature.

\section{Data extraction and analysis}

Bibliometric data (number of authors, publication year, origin, journal of publication), data on participants (population, sample size, mean age, gender, education) and intervention data (intervention components, control groups, delivery mode, number of sessions/modules, session duration, and type of positive psychology activities) were extracted by the first author. Two authors classified WEIRD indicators in the following ways. Data were analyzed descriptively using SPSS ${ }^{\circledast}$ version 23 and Microsoft Excel ${ }^{\circledR}$.

\section{Western}

Following Gosling, Sandy, John, and Potter (2010), we classified North America, Western Europe, Israel, Australia and New Zealand as Western-societies. We also examined the number of participants explicitly identified as Caucasian or non-Caucasian. Finally, we examined if the interventions in the studies were culturally adapted, that is, if there was evidence of systematic modification of evidence-based treatments (EBT) or intervention protocols so that they were made compatible with the cultural patterns, meanings, and values of participants in the intervention (Bernal \& Domenech Rodriguez, 2012).

\section{Educated}

Education was assessed using two methods. At the macro-level, the level of human development in a specific country was used as an indicator for the education level. This was done on the basis of the data from the Human Development Report (2015) that classified the general population of the country as having a very high, high, medium, or low level of human development (United Nations Development Programme, 2015). We also analyzed education on an individual level and report the numbers and percentages of study participants who received a higher education (attended college or university for at least one year).

\section{Industrialized}

The term 'industrialized' is often associated with a high level of economic and technological development of a country. We classified countries as having an advanced economy or an emerging/developing economy on the basis of data from the World Economic Outlook (International Monetary Fund, 2016). Countries that are described as advanced economies are characterized by high gross domestic product (GDP) and a high degree of industrialization (International Monetary Fund, 2016). Countries classified as emerging/developing economies are markets with high growth expectations, characterized by a high level of risk and extremely volatility (Mody, 2004).

\section{Rich}

As few individual studies report demographics on the income level of the participants, we primarily used country data from the Global Wealth Databook (2013) that aims to provide the best available estimates of the wealth-holding of households worldwide (Credit Suisse, 2013). In order to be exhaustive, we also reviewed the income of study participants in studies in which this information was reported.

\section{Democratic}

Classification of the state of democracy was based on the Democracy Index as compiled by the Economist Intelligence Unit (Kekic, 2008).

\section{Results}

\section{General bibliometrics}

We identified a total of 8,248 records. After removal of duplicates, 7,136 records remained. These records were screened by the first and third author, after which 301 records were found to be eligible. Of these records, 114 articles were excluded. We finally included 187 articles in our bibliometric analysis that consisted of 188 original studies. Figure 1 shows the results of the literature search.

Since 1998 was considered as the year of the conception of the positive psychology movement, the earliest year of publication was 1998 with two studies, followed by two years in which no RCTs were published. Between 2001 and 2009, the number of studies varied from two to four per year, except for a peak of twelve studies in 2006. In 2009, there were eight published studies, in 2010 the number dropped to five. From 2011, there is a steady rise in the number of studies, with peaks in 2014 (33 studies) and 2016 (49 studies). An overview is depicted in Figure 2. In the period from 1998 to 2007 no publications from non-Western countries were published on a yearly basis, with the exception in 2004 with one study from China. During the period 2008 - 2016 every year a minimum of one RCT from a non-Western country was published.

The studies were published in 118 different journals, and the following journals published three or more studies: The Journal of Positive Psychology $(n=24$, 12.2\%), Journal of Happiness Studies ( $n=8,4.3 \%)$, Journal of Clinical Psychology ( $n=7,3.7 \%)$, Journal of Consulting and 


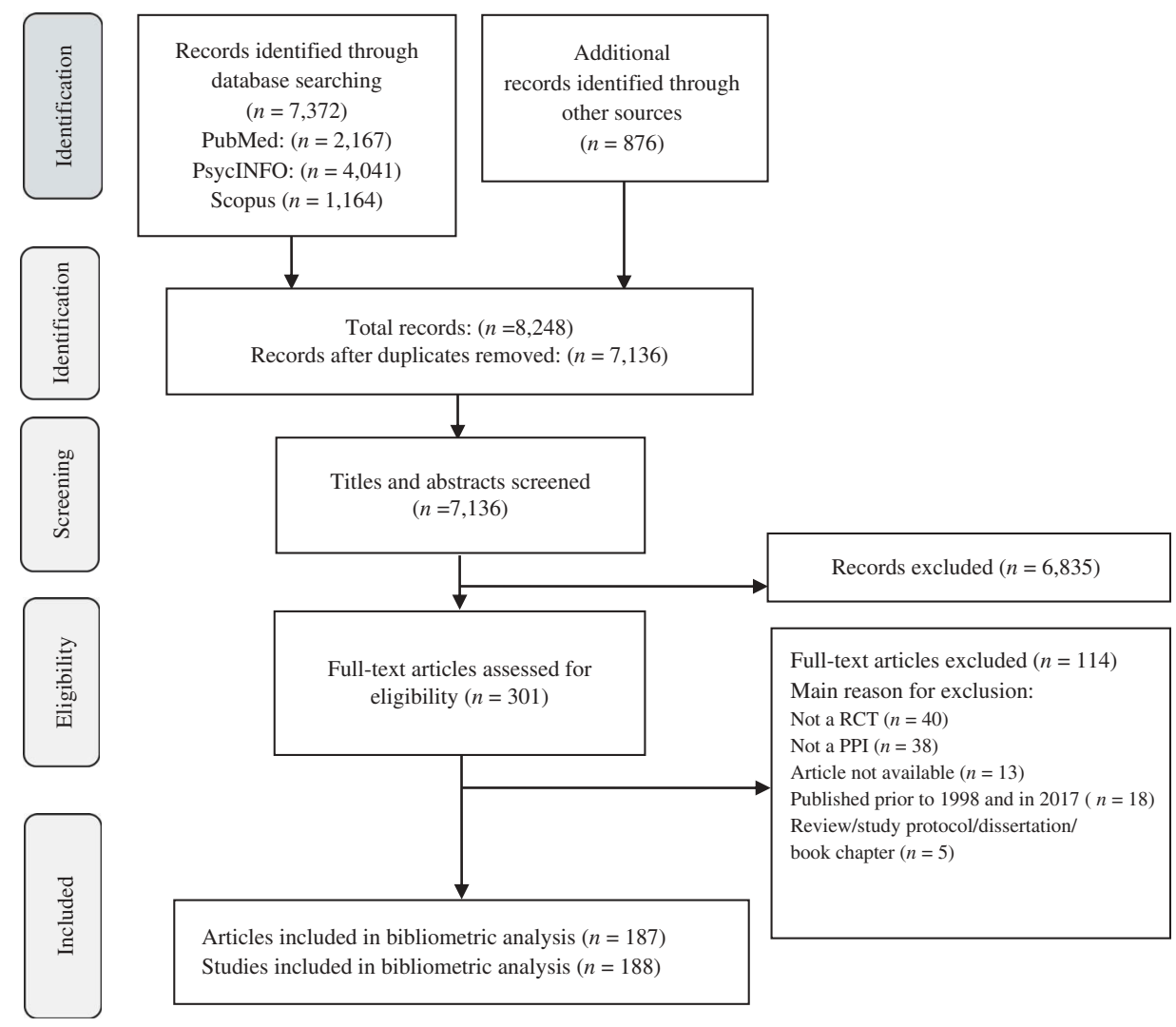

Figure 1. Results of literature search.

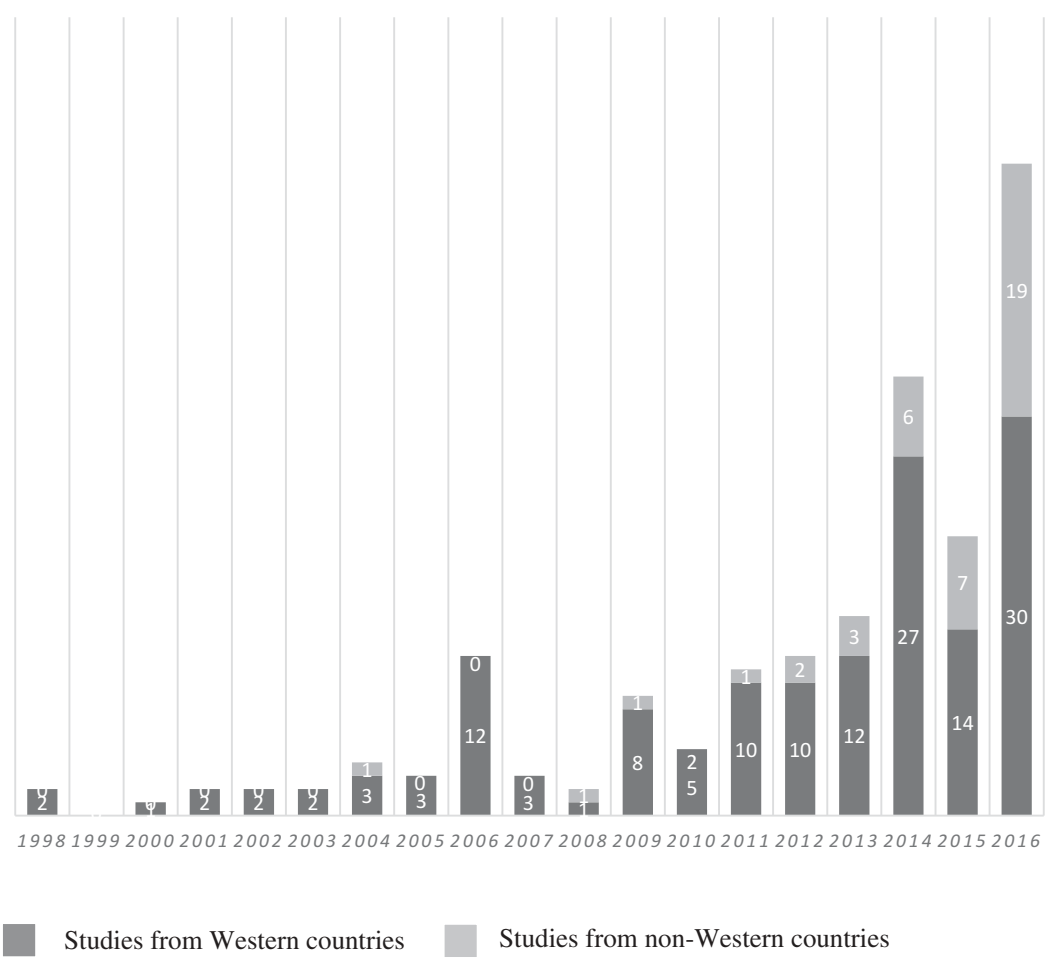

Figure 2. Randomized controlled trials on positive psychology interventions through time. 
Clinical Psychology ( $n=4,2.1 \%)$, Journal of Medical Internet Research $(n=4,2.1 \%)$, Aging \& Mental Health $(n=3,1.6 \%)$, American Psychologist ( $n=3,1.6 \%)$, Frontiers in Psychology ( $n=3,1.6 \%)$, International Journal of Geriatric Psychiatry ( $n=3,1.6 \%)$, Journal of Personality and Social Psychology $(n=3,1.6 \%)$, and Social Indicators Research $(n=3,1.6 \%)$.

\section{Participants}

A total of 43,582 individuals participated in 188 RCTs. Study sample sizes ranged from 10 to 3,363 (median $=83.0$ ). The mean age of the participants was 37.1 ( 29 studies did not report the mean age of the participants). There were 164 (87.2\%) studies that included adults, of which 10 (5.3\%) were elderly (older than 62 years). Twenty-two studies (11.7\%) included children or adolescents and 2 studies (1.1\%) included both adults and children. Sixty-six studies were conducted among clinical populations (35.1\%) and 122 studies among non-clinical populations (64.9\%). For the clinical population, the two most frequently studied conditions were depression ( $n=13,19.7 \%$ of the clinical population) and cancer ( $n=10,15.2 \%)$. Other categories were patients with addiction problems $(n=5,7.6 \%)$, patients with affective disorders $(n=5,7.6 \%)$, patients with cardiac problems $(n=4,6.1 \%)$, patients with chronic pain $(n=3,4.5 \%)$, HIV/AIDS patients $(n=3,4.5 \%)$, patients with traumatic brain injury $(n=3,4.5 \%)$, patients with diabetes $(n=2,3.0 \%)$, patients with PTSD $(n=1,1.5 \%)$, and women with fertility problems $(n=1,1.5 \%)$. Twelve studies did not specify the nature of the physical or psychological problems (18.3\%). The non-clinical population consisted of healthy adults ( $n=59,48.4 \%)$, university/ college students $(n=39,32.0 \%)$, school children/adolescents $(n=15,12.3 \%)$, and elderly ( $n=9,7.4 \%)$. The proportion of female participants at baseline assessment ranged from $0 \%$ (5 RCTs, $2.7 \%$ ) to $100 \%$ (30 RCTs, 16.0\%), with a median of $72.0 \%(I Q R=29.4)$. Seven RCTs $(3.7 \%)$ did not report the proportion of female participants at baseline assessment. The total number of women participating in the 180 remaining studies is 29,889 , which is $73.7 \%$ of the population in the 180 studies.

\section{Interventions}

We made the distinction between single component intervention studies and multi-component intervention studies. Single component intervention studies usually consist of one or two single positive psychology activities. Multi-component positive psychology interventions (MPPIs) are interventions that are composed of a minimum of three positive psychology activities that follow one or more of the following pathways: i) savoring (intensifying and prolonging momentary pleasurable experiences); ii) expressing gratitude (through reflection and activities of expression); iii) engaging in acts of kindness; iv) promoting positive relationships; v) promoting meaning and purpose (Hendriks et al., 2017; Schueller \& Parks, 2014; Schueller, Kashan, and Parks, 2014). Our analysis contained 118 single component interventions (62.8\%) and 70 multi-component interventions (37.2\%). Interventions were delivered in the followings ways: group based ( $n=98,52.0 \%$ ), individual $(n=11,5.9 \%)$, and self-help $(n=79,42.1 \%)$. Thirty-two selfhelp studies were delivered online (17.1\%). It should be noted that one group-based interventions provided additional individual sessions, two individual interventions provided an online supplement, and thirty-two self-help studies were delivered completely online.

\section{Positive psychology activities}

In our analysis, we included 169 studies (89.9\%) that specified the positive psychology activities; we excluded 19 studies (10.1\%) that provided only information on the themes or the domains of the modules, or an incomplete overview of the activities. Similar activities were often presented under different names. Finally, we categorized the activities into 15 types of positive psychology activities (See Appendix I). We found that activities that focus on the recollection of positive feelings were the most frequently used activities. Other popular positive psychology activities include positive psycho-education, identifying and using strengths and virtues, the expression of gratitude, acts of kindness, and positive thinking. A complete overview is shown in Table 1.

When comparing the activities used in non-Western versus Western studies (and considering the overall ratio of 1:3.6), we can conclude that life review (positive reminiscence) and spiritual activities are used considerably more often, whereas acts of kindness, mindfulness, best possible selves and physical activities are used considerably less often in non-Western countries.

\section{WEIRD bibliometrics}

\section{Western}

We found that 147 studies (78.2\%) originated from Western countries compared to 41 studies (21.8\%) from non-Western countries. The studies were conducted in 24 different countries; the 14 Western countries were Australia, Belgium, Canada, Finland, Germany, Ireland, Israel, Italy, Norway, the Netherlands, Spain, Switzerland, United Kingdom, and the United States. The ten non-Western countries were China, India, Iran, Japan, Malaysia, the Philippines, South Africa, South Korea, Taiwan, and Turkey. We witnessed a sharp increase in the number of studies from non-Western 
Table 1. Overview positive psychology activities.

\begin{tabular}{|c|c|c|c|c|c|c|}
\hline \multirow[b]{2}{*}{ Positive activity } & \multicolumn{2}{|c|}{ Total } & \multicolumn{2}{|c|}{ non-Western } & \multicolumn{2}{|c|}{ Western } \\
\hline & $\#$ & $\%$ & \# & $\%$ & \# & $\%$ \\
\hline Positive recollection & 85 & $50.3 \%$ & 18 & $10.7 \%$ & 67 & $39.6 \%$ \\
\hline Positive psycho-education & 46 & $27.2 \%$ & 13 & $7.7 \%$ & 33 & $19.5 \%$ \\
\hline Strengths and Virtues & 40 & $23.7 \%$ & 11 & $6.5 \%$ & 29 & $17.2 \%$ \\
\hline Gratitude expression & 37 & $21.9 \%$ & 11 & $6.5 \%$ & 26 & $15.4 \%$ \\
\hline Acts of kindness & 36 & $21.3 \%$ & 6 & $3.6 \%$ & 30 & $17.8 \%$ \\
\hline Positive thinking & 35 & $20.7 \%$ & 9 & $5.3 \%$ & 26 & $15.4 \%$ \\
\hline Goal setting & 31 & $18.3 \%$ & 10 & $5.9 \%$ & 21 & $12.4 \%$ \\
\hline Mindfulness & 31 & $18.3 \%$ & 6 & $3.6 \%$ & 25 & $14.8 \%$ \\
\hline Life review & 30 & $17.8 \%$ & 14 & $8.3 \%$ & 16 & $9.5 \%$ \\
\hline Forgiveness & 26 & $15.4 \%$ & 6 & $3.6 \%$ & 20 & $11.8 \%$ \\
\hline Meaningful activities & 23 & $13.6 \%$ & 4 & $2.4 \%$ & 19 & $11.2 \%$ \\
\hline Best possible self & 21 & $12.4 \%$ & 2 & $1.2 \%$ & 19 & $11.2 \%$ \\
\hline Spiritual activities & 14 & $8.3 \%$ & 6 & $3.6 \%$ & 8 & $4.7 \%$ \\
\hline Healthy life style & 11 & $6.5 \%$ & 0 & $0.0 \%$ & 11 & $6.5 \%$ \\
\hline Self-compassion & 11 & $6.5 \%$ & 3 & $1.8 \%$ & 8 & $4.7 \%$ \\
\hline
\end{tabular}

origins through time (See Figure 2). In the period from 1998 through 2007, we only found 1 published study of non-Western origin, which was published in 2004. From 2008 to 2011, an average of 0.75 studies per year was published. Since 2012, the number has been rising sharply. In 2012, there were two published studies (16.7\%): one from Iran and one from Japan. In 2013, three studies (20\%) from non-Western countries were published: two from China and one from South Korea. In 2014, there were six studies (18.2\%): two from China, one each from India, Iran, Japan, and South Africa. In 2015, seven studies (33.3\%): three from China, two from Iran, one from India and one from Turkey. Finally, in 2016 there were 19 published studies (38.8\%): seven from China, five from Iran, two from South Korea, and one each from India, Japan, Malaysia, the Philippines, and Taiwan. Over the past 20 years, the ratio of nonWestern versus Western RCTs has increased from 1:13.3 in the period $1998-2011$, to an average of 1:2.6 in the period 2012 - 2016. This is shown in Table 2.

Most studies were conducted in the United States ( $n=74,39.4 \%)$, followed by Australia ( $n=18,9.6 \%$ ), China ( $n=15,8.0 \% ; n=10,5.3 \%$ in Hong Kong and $n=5,2.7 \%$ in the mainland of China), Iran ( $n=10,5.3 \%)$, and the United Kingdom ( $n=10,5.3 \%$ ). Countries where five to nine studies were conducted were: Switzerland ( $n=9,4.8 \%)$, the Netherlands $(n=8,4.3 \%)$, Canada $(n=6,3.2 \%)$, and Spain $(n=6,3.2 \%)$. Countries where two to five studies were conducted were Germany $(n=4$, $2.1 \%)$, India $(n=3,1.6 \%)$, Ireland $(n=3,1.6 \%)$, Italy $(n=3$, $1.6 \%)$, Japan $(n=3,1.6 \%)$, South Korea $(n=3,1.6 \%)$, Taiwan $(n=3,1.6 \%)$, Israel $(n=2,1.1 \%)$, and Norway $(n=2,1.1 \%)$. Countries where one study $(0.5 \%)$ per country was conducted were Belgium, Finland, Malaysia. the Philippines, South Africa, and Turkey. Table 3 also contains the overview of the country origins.

Sixty-two studies from Western origins reported the ethnicity of the participants: from a total of 8,713
Table 2. Ratio non-Western versus western publications.

\begin{tabular}{lccl}
\hline Year & \# non-Western RCTs & \# Western RCTs & Ratio \\
\hline $1998-2011$ & 4 & 53 & $1: 13.3$ \\
2012 & 2 & 11 & $1: 5.5$ \\
2013 & 3 & 12 & $1: 4.0$ \\
2014 & 6 & 27 & $1: 4.5$ \\
2015 & 7 & 14 & $1: 2.0$ \\
2016 & 19 & 30 & $1: 1.6$ \\
& & & $1: 3.6$ \\
\hline
\end{tabular}

participants, 5,936 were Caucasian (68.1\%) and 2,777 were non-Caucasian (31.9\%). Although not specifically reported in all studies from non-Western origins, we believe it is fair to assume all participants from these 41 studies ( $n=11,266)$ to be non-Caucasian, bringing the total (estimated) number of non-Caucasian participants to $14,183(32.2 \%)$ of the entire population. In addition, we examined whether the interventions were culturally adapted or not. We found 17 (41.5\%) studies using intervention programs that were culturally adapted, and 24 (58.5\%) studies in which the programs were not culturally adapted (including four studies in which there was no clear description).

\section{Education}

In total, 17 (70.8\%) countries were characterized by very high human development, two (8.3\%) countries were characterized by high human development and three $(12.5 \%)$ countries were characterized by medium human development (See Table 3). It should be noted that mainland China is indicated as having high human development, whereas Hong Kong, China is indicated as having very high human development (10 studies). Data from Taiwan were not available. However, since Taiwan is known as one of the five so-called 'Asian economic tigers' we believe it is reasonable to assume the level of education is comparable to South Korea and Hong Kong. Thus, Taiwan is classified as having very high human development. On an individual level, it was possible to partly analyze the educational level of populations in the trials: $98(52.1 \%)$ studies provided sufficient information. We found that from the 17,627 participants in these 98 studies, 12,771 participants (72.4\%) had a relatively high educational level, having attended at least one year of college.

\section{Industrialized}

The economies of 17 (70.8\%) countries were classified as advanced (See Table 3). These countries include all Western countries and three non-Western countries (Japan, South Korea, and Taiwan). Six countries (25.0\%) were classified as emerging and developing economies (India, Iran, Malaysia, the Philippines, South Africa, and Turkey). China (4.2\%) is considered to have 


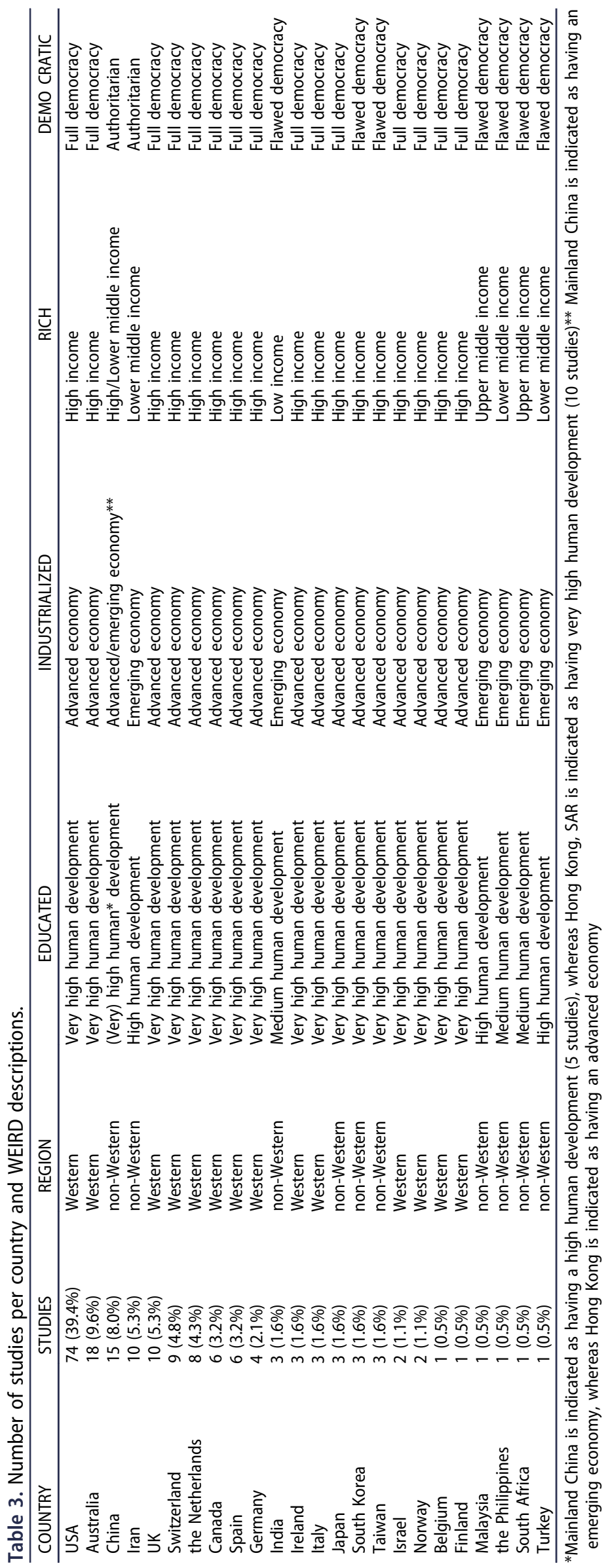


an emerging economy, and Hong Kong, SAR to have an advanced economy. One hundred sixty-six (88.3\%) of the studies were conducted in countries with an advanced economy (including 10 studies from Hong Kong, China) and twenty-two studies (11.7\%) were conducted in countries with an emerging economy (including 5 studies from mainland China).

Rich. Seventeen (70.8\%) countries were classified as high-income countries (HIC) (See Table 3). These countries again include all Western countries, Japan, South Korea, and Taiwan. Two non-Western countries (8.3\%) were classified as an upper middle-income country (South Africa, Malaysia), three (1.5\%) as lower middleincome countries (Iran, the Philippines, Turkey), and India as a low-income country (4.2\%). China was classified as a lower middle-income country, while Hong Kong SAR was classified as a high-income country (Credit Suisse, 2013). One hundred sixty-six (88.3\%) of the studies were conducted in high-income countries (HICs) including 10 studies from Hong Kong, China. Twenty-two studies (11.7\%) were conducted in lowand middle-income countries (LMICs). On an individual level, income was reported in only 14 studies from Western countries (7.4\%) and three studies from nonWestern countries (1.6\%). In light of this limited number of studies, particularly in non-Western countries, we are unable to draw any meaningful conclusions.

\section{Democratic}

Fifteen (62.5\%) countries were classified as full democracies and these include all Western countries (See Table 3). Six non-Western countries were either classified as flawed democracies (India, Malaysia, the Philippines, South Africa, South Korea, and Taiwan, in total 25.0\%), two countries were authoritarian (China and Iran, in sum 8.3\%). In light of recent developments, we have also classified Turkey as a flawed democracy (4.2\%) (Kekic, 2008). One hundred fifty $(79.8 \%)$ of the studies were conducted in countries with a full democracy, $13(6.9 \%)$ in countries with flawed democracies, and 25 (13.3\%) studies were conducted in countries with authoritarian regimes.

\section{General discussion}

The purpose of this study was to examine trends in the publication of RCTs in positive psychology and to determine to what extent positive psychology is currently Western-centric. Findings reveal an incremental growth in the number of RCTs on the effects of positive psychology, suggesting an increasing interest in research on the efficacy of PPIs. These findings are in line with a previous bibliometric analysis on the growth of positive psychology that included peer-reviewed journal articles, authored books, edited books, book reviews, and dissertations (Schui \& Krampen, 2010). Our analysis also showed that until recently positive psychology was indeed culturally biased since the large majority of the RCTs originated from Western countries. However, since 2014, we witness a sharp rise in publications from non-Western countries that now account for over one-third of the studies. This suggests that there is a growing trend in PPIs towards globalization. Analysis revealed that life review and spiritual activities were the most frequently used activities in non-Western countries. Activities that were used much less frequently compared to Western PPI's, were acts of kindness, mindfulness, best possible selves, and physical activities. In addition, we found that 24 interventions (58.5\%) from non-Western studies were not culturally adapted. Some exercises are already highly adaptive and perhaps culture-free. Life review (positive reminiscence), for example, focuses on an individual's personal memories (Lau \& Cheng, 2011) which are usually tied to a specific cultural and historical setting, and therefore, may be applied universally. In other studies, the interventions were based on a specific protocol that was developed in the West, for example, the Positive Psychotherapy (PPT) protocol. In 17 studies (41.5\%) the interventions were culturally adapted, for example, by shifting the focus of the intervention from the individual to their relationships with family and community members. A study involving 2,070 participants in Hong Kong aimed to increase subjective well-being and health-related quality of life by fostering positive communication among families. This was done by conducting regular positive psychology activities such as positive reminiscence and expression of gratitude in cooking and dining with family members (Ho et al., 2016). Emic meditation practices can also be integrated into PPIs to ensure a better cultural fit. This was done in a study among 78 Hong Kong school teachers in which regular counting-your-blessings exercises were supplemented by Naikan-meditation-like questions, bringing the exercise in line with Confucian teachings of daily self-reflection (Chan, 2013). Studies from Iran have examined the effects of Islam-based PPIs where gratitude towards Allah is actively expressed, or strengths and virtues that are prominently featured in the Qur'an are practiced (Al-Seheel \& Moor, 2016; Rouholamini, Kalantarkousheh, \& Sharifi, 2016).

So why is it important to know how much research actually stems from non-Western countries? A frequently voiced concern by cross-cultural psychologists and the international research community is that science is an enterprise that predominantly consists of researchers from Western countries, and that findings from studies among Western populations are frequently generalized to populations in non-Western countries (Berry, 2013; 
Sue, 1999). Traditional psychology is a science that was developed in the West and positive psychology is a movement that was initiated by American psychologists (Seligman \& Csikszentmihalyi, 2000). At first glance, the roots of positive psychology seem to lie in the typical American tradition of 'positive' individualism (Díaz \& González, 2012), propagating the idea that with enough effort and determination 'every underdog can become a millionaire.' However, our analysis tells a more complex story. In practice, many PPls integrate knowledge and activities that are rooted in Eastern philosophies, in particular, Buddhism (Cassaniti, 2014; Levine, 2011; Walsh, 2015). We found that PPIs often include exercises in mindfulness and cultivate self-compassion and compassion for others. Although the aim of activities involving gratitude, practicing forgiveness and acts of kindness are targeted at improving individual well-being, many do so via establishing better relationships with others. While their goal may be individualistic, these activities work through collectivistic pathways. For example, writing a gratitude letter is an individual activity, but it is the interaction of an individual with the social environment during the accompanying gratitude visit that may contribute to the positive changes (Seligman, Steen, Park, \& Peterson, 2005). Gratitude expression can also be practiced in the context of the family, as the previously mentioned cluster RCT among 2,070 participants in Hong Kong demonstrated (Ho et al., 2016). Other examples of community-based PPIs that focus on improving social relationships can be found in studies from South Africa (Eloff et al., 2014), China (Ho et al., 2016), and India (Leventhal et al., 2016, 2015). By unjustly discarding positive psychology as a Western-ethnocentric science, the legitimacy of the movement and its interventions are undermined. This may hamper the search for new and evidence-based methods to increase well-being among the global population.

With a growing focus on diversity in health care, we believe that it is important for positive psychologists to be aware of cultural differences. Cross-cultural studies have shown that Western-derived interventions combating mental health threats such as depression, posttraumatic stress disorders or suicidal behavior can conflict with local ideas of appropriate social interaction, norms regarding privacy, dignity, and family solidarity (Wickramage, 2006). While such interventions may be effective in Western countries, they may not be so in different cultural settings, or they may even be harmful (Ganesan, 2006). For example, emotional disclosure may increase anxiety and stress, lead to family conflict, or stigmatization (Christopher, Wendt, Marecek, \& Goodman, 2014). While the concept of happiness across cultures has been studied widely (Diener \& Suh, 2000; Joshanloo, 2014; Selin \& Davey, 2012; Veenhoven,
2012) and there are several studies on cultural differences on expression of positive emotions (Leu, Wang, \& Koo, 2011; Ong, Bergeman, Bisconti, \& Wallace, 2006; Tugade \& Fredrickson, 2004), a cross-cultural approach to positive psychology in general is still in its infancy.

The trend towards a growing number of studies evaluating the impact of PPIs in non-Western countries has an important implication. PPIs have the potential to partially overcome one of the largest obstacles that mental health care faces in low- and middle-income countries (LMICs), namely the so-called 'treatment gap'. Up to $75 \%$ of people in need of mental health care in LMICs do not receive any treatment because traditional psychological interventions are often costly and cannot be implemented on a large scale due to scarcity of mental health professionals (Kohn, Saxena, Levav, \& Saraceno, 2004; Saraceno et al., 2007). PPIs, however, consist of activities that are relatively simple which allow PPIs to be conducted by local lay counselors who have a less formal education. In this way, PPIs can contribute to scaling-up of services for mental health care. The WHO describes scaling-up as planned efforts to increase the impact of health service innovations that are successfully tested in pilot or experimental projects to benefit more people and to foster policy and program development on a lasting basis (Simmons, Fajans, \& Ghiron, 2007). Scaling-up is one of the primary concerns in Global Mental Health (Eaton et al., 2011; Meffert, Neylan, Chambers, \& Verdeli, 2016). We do, however, emphasize that for the treatment of severe mental disorders highly skilled mental healthcare professionals are irreplaceable.

In addition to overcoming the treatment gap, the field of positive psychology has opened up ways to study constructs that are important in various religious and spiritual traditions (Falb \& Pargament, 2014). Many PPIs have already integrated activities in the domain of spirituality and religion (Rye, Wade, Fleri, \& Kidwell, 2013). In this way PPIs are suitable for non-Western populations, considering that these populations often subscribe to a twotiered vision of the world (Taylor, 1985). In a twotiered system a belief in a particular cosmological framework is the foundation for understanding life and giving meaning to one's everyday experiences, whereas in a one-tiered system the process of meaning giving is a personal, cognitive one (Christopher \& Hickinbottom, 2008). Because of the inclusion of spiritual themes, PPIs can easily be adapted to different cultural settings, as demonstrated by Islamic based PPIs that were conducted in Iran (AI-Seheel \& Moor, 2016; Rouholamini et al., 2016; Saeedi, Nasab, Zadeh, \& Ebrahimi, 2015). 
PPIs may also counter another reason why people with mental health problems in developing countries do not seek help, namely, the fear for stigmatization, either self-stigma or affiliated stigma (Abdullah \& Brown, 2011; Hinton \& Laroche, 2012; Mascayano, Armijo, \& Yang, 2015). PPIs may bypass this problem because they are focused on enhancing positive thoughts, feelings, and behaviors (Sin \& Lyubomirsky, 2009), and through the practice of gratitude, optimism, acts of kindness, meditation, and other activities that are not stigmatizing (Layous, Chancellor, Lyubomirsky, Wang, \& Murali Dorais, 2011). The development of character strengths, such as social intelligence and kindness, may even contribute to reducing the stigmatization of those who seek help for mental health problems (Vertiloa \& Gibson, 2014). Finally, many positive psychology activities rely on the intuition and feelings of the participants, rather than analytical thinking. Perhaps PPIs are even more suitable and effective in nonWestern countries than traditional psychological interventions such as psycho-therapy and cognitive behavioral therapy since non-Western populations have a more holistic view on life and an intuitive approach to thinking (Talhelm et al., 2015).

\section{Limitations}

The contributions of this paper should be viewed in light of certain limitations. Firstly, we only included randomized controlled trials in this bibliometric analysis. RCTs are often cost intensive and complex (Korn \& Freidlin, 2012), and therefore may be a lesser used research design in non-Western countries. For example, an article on the progress of positive psychology in India reported eight recent studies on the effects of PPIs in India (Ghosh \& Deb, 2016), but none of the studies were RCTs. In our analyses we identified 265 articles published in the Indian Journal of Positive Psychology, but only two of the studies $(0.3 \%)$ were RCTs. It is very likely that if we were to include other study designs, such as quasi-experimental and observational studies, the percentage of nonWestern studies would increase. Secondly, our findings suggest that the so-called "10/90 gap" in positive psychology is improving. This term refers to the claim that only ten percent of global health research is spent on improving the conditions of people in low-income countries that account for 90 percent of the global population (Luchetti, 2014; Vidyasagar, 2006). Perhaps there is an overall trend towards global health equity, and the aforementioned gap in mental health research is closing in general. However, due to a paucity of recent research, we cannot compare our findings to data from bibliometric analyses or reviews outside the field of positive psychology. There might also be regional differences within the same country that are not captured (Talhelm et al., 2015), but we believe our study still offers insights that are more nuanced than otherwise available in the field. A third limitation pertains to the term WEIRD itself. While this may be a catchy acronym, and it is clear what it intends to describe, the individual factors that form the acronym may not be equally informative. Furthermore, it can be argued that the distinction between Western and non-Western is incorrect, because what is considered 'western', depends on the geographical location of the observer. The distinction between high-income countries (HICs) and low- and middle-income countries (LMICs) may be more suitable. Another option is the distinction between countries with independent versus interdependent cultures (Shin \& Lyubomirsky, 2017). Also, there is another factor that may lead to a generalization bias and which is not included in the acronym, namely gender. Our study found that $71.2 \%$ of the total study population is female. As mirrored in other reviews (e.g. Rao \& Donaldson, 2015), this suggests a strong gender bias in terms of study participation.

\section{Recommendations}

Firstly, we recommend research in the field of positive psychology from non-Western countries to continue to develop culturally sensitive PPIs. This can be done, for example, by matching the characteristics of the intervention and its intended population (La Roche \& Lustig, 2010). Good examples of such an approach are the aforementioned Islam-based PPIs from Iran (Al-Seheel \& Moor, 2016; Rouholamini et al., 2016; Saeedi et al., 2015) and the 'Happy Kitchen Family project' (Ho et al., 2016). The process of cultural adaptation of interventions has been widely described by leading authors in the field of cross-cultural psychology (Domenech Rodríguez \& Bernal, 2012; Hinton \& Jalal, 2014; Hinton \& La Roche, 2013; Kirmayer, 2006). Whereas cultural psychiatry focuses on the cultural idioms of distress (Hinton \& Lewis-Fernández, 2010), positive crosscultural psychology could concentrate on discovering culturally salient indicators of well-being. For example, a qualitative study conducted in Suriname, South America found that the concept of rukun is associated with resilience among the Javanese ethnic group (Hendriks, Graafsma, Hassankhan, Bohlmeijer, \& de Jong, 2017). Rukun can be described as living in harmony with one surrounding, which includes the spiritual world. Another example in the context of Suriname is opo yeye, a mental well-being model based on traditional knowledge of the winti belief system among Afro-Surinamese (Cairo, 2012). We recommend use of a mixed method approach (Teddlie \& Tashakkori, 2011) to discover emic models and expressions 
of well-being. Secondly, we recommend that organizations that strive to promote the dissemination of positive psychology should actively reach out to researchers in nonWestern countries, for example, by attending regional psychology conferences in non-Western countries, or inviting leading cross-cultural researchers as speakers at positive psychology conferences. Finally, we recommend the examination of the efficacy of PPIs from non-Western countries, including a moderator analysis including WEIRD and other factors (for example the influence of gender, and if an intervention was culturally adapted or not).

\section{Conclusion}

Although, positive psychology is still a science dominated by WEIRD populations, we see a strong trend towards a more global distribution of scientific productivity over the past four years. The ratio of non-Western to Western RCTs has dropped from 1:13 during the period from 1998 to 2012, to an average of 1:2.6 over the past four years, with China and Iran now in the top five of countries that produce the most RCT publications in the field of positive psychology. Although the majority of the studies on positive psychology is still from Western countries, there is much promise of positive psychology expanding globally.

\section{Disclosure statement}

No potential conflict of interest was reported by the authors.

\section{References}

Abdullah, T., \& Brown, T. L. (2011). Mental illness stigma and ethnocultural beliefs, values, and norms: An integrative review. Clinical Psychology Review, 31(6), 934-948.

Allik, J. (2013). Personality psychology in the first decade of the new millennium: A bibliometric portrait. European Journal of Personality, 27(1), 5-14.

Al-Seheel, A. Y., \& Moor, N. M. (2016). Effects of an Islamicbased gratitude strategy on Muslim students' level of happiness. Mental Health, Religion \& Culture, 19(7), 686-703.

Arnett, J. J. (2008). The neglected 95\%: Why American psychology needs to become less American. American Psychologist, 63(7), 602.

Becker, D., \& Marecek, J. (2008). Positive psychology. History in the remaking? Theory \& Psychology, 18(5), 591-604.

Bernal, G., \& Domenech Rodriguez, M. M. (2012). Cultural adaptation in context: Psychotherapy as a historical account of adaptations. In M. M. D. R. E. G. Bernal (Ed.), Cultural adaptations: Tools for evidence-based practice with diverse populations (pp. 3-22). Baltimore, MD: United Book Press, Inc.

Berry, J. W. (2013). Global psychology. South African Journal Of Psychology, 43(4), 391-401. doi:10.1177/0081246313504517

Bolier, L., Haverman, M., Westerhof, G. J., Riper, H., Smit, F., \& Bohlmeijer, E. T. (2013). Positive psychology interventions:
A meta-analysis of randomized controlled studies. BMC Public Health, 13, 119.

Cairo, A. (2012). Yeye Sani: An Afro-Surinamese concept of the self in a model of mental well-being. Mental Health, Religion \& Culture, 15(5), 467-483.

Cameron, K. (2016). Adressing criticism of positive psychology and positive organizational scholarship. Canadian Positive Psychology Association Conference, Niagara on the Lake.

Casellas-Grau, A., Font, A., \& Vives, J. (2014). Positive psychology interventions in breast cancer. A systematic review. Psycho-Oncology, 23, 9-19.

Cassaniti, J. L. (2014). Buddhism and positive psychology: Religion and spirituality across cultures. Dordrecht, the Netherlands: Springer.

Chakhssi, F., Kraiss, J. T., Sommers-Spijkerman, M., \& Bohlmeijer, E. T. (2018). The effect of positive psychology interventions on well-being in clinical populations: A systematic review and meta-analysis. BMC Psychiatry, 18, 211.

Chan, D. W. (2013). Counting blessings versus misfortunes: Positive interventions and subjective well-being of Chinese school teachers in Hong Kong. Educational Psychology, 33(4), 504-519.

Christopher, J. C., \& Hickinbottom, S. (2008). Positive psychology, ethnocentrism, and the disguised ideology of individualism. Theory \& Psychology, 18(5), 563-589.

Christopher, J. C., Wendt, D. C., Marecek, J., \& Goodman, D. M. (2014). Critical cultural awareness: Contributions to a globalizing psychology. American Psychologist, 69(7), 645.

Cole, M. (2006). Internationalism in psychology: We need it now more than ever. American Psychologist, 61(8), 904.

Coyne, J. C., \& Tennen, H. (2010). Positive psychology in cancer care: Bad science, exaggerated claims, and unproven medicine. Annals of Behavioral Medicine, 39, 15-26.

Credit Suisse. (2013). Global Wealth Databook 2013. Zurich: Crédit Suisse. Retrieved from https://publications.creditsuisse.com/tasks/render/file

Díaz, E. C., \& González, J. C. S. (2012). The roots of positive psychology. Papeles Del Psicólogo, 33(3), 172-182.

Dickens, L. R. (2017). Using gratitude to promote positive change: A series of meta-analyses investigating the effectiveness of gratitude interventions. Basic and Applied Social Psychology, 39(4), 193-208.

Diener, E., \& Suh, E. M. (Eds.). (2000). Culture and subjective well-being. Cambridge, MA: MIT press.

Domenech Rodríguez, M. M., \& Bernal, G. (2012). Bridging the gap between research and practice in a multicultural world. In G. Bernal \& M. Domenech Rodríguez (Eds), Cultural adaptations. Tools for evidence based practice with diverse populations (pp. 265-288). Washington, DC: American Psychological Association.

Eaton, J., McCay, L., Semrau, M., Chatterjee, S., Baingana, F., Araya, R., \& Saxena, S. (2011). Scale up of services for mental health in low-income and middle-income countries. The Lancet, 378(9802), 1592-1603.

Eloff, I., Finestone, M., Makin, J. D., Boeving-Allen, A., Visser, M., Ebersöhn, L., \& Forsyth, B. W. (2014). A randomized clinical trial of an intervention to promote resilience in young children of HIV-positive mothers in South Africa. AIDS, 28 (3), S347.

Eysenck, M. W. E. (2001). How do European and US psychology differ? The Psychologist, 14, 353-355. 
Falb, M. D., \& Pargament, K. I. (2014). Religion, spirituality, and positive psychology: Strengthening well-being. In J. Teramoto Pedrotti \& L. Edwards (Eds.), Perspectives on the intersection of multiculturalism and positive psychology (pp. 143-157). New York, NY: Springer.

Frawley, A. (2015). Happiness research: A review of critues. Sociology Compass, 9(1), 62-77.

Ganesan, M. (2006). Psychosocial response to disasters-Some concerns. International Review of Psychiatry, 18(3), 241-247.

Ghosh, A., \& Deb, A. (2016). Positive psychology progress in India: Accomplishments and Pathways ahead. Psychological Studies, 61(3), 113-125.

Gosling, S. D., Sandy, C. J., John, O. P., \& Potter, J. (2010). Wired but not WEIRD: The promise of the Internet in reaching more diverse samples. Behavioral and Brain Sciences, 33(23), 94-95.

Hendriks, T., Graafsma, T., Hassankhan, A., Bohlmeijer, E., \& de Jong, J. (2017). Strengths and virtues and the development of resilience: a qualitative study in suriname during a time of economic crisis. International Journal of Social Psychiatry, 64(2), 180-188.

Hendriks, T., Schotanus- Dijkstra, M., Hassankhan, A., Graafsma, T., de Jong, J., \& Bohlmeijer, E. T. (2017). The efficacy of multicomponent positive psychology interventions: A systematic review and meta-analysis. Manuscript Submitted for Publication.

Henrich, J., Heine, S. J., \& Norenzayan, A. (2010a). Most people are not WEIRD. Nature, 466(7302), 29.

Henrich, J., Heine, S. J., \& Norenzayan, A. (2010b). The Weirdest people in the world? Behavioral and Brain Sciences, 33, 61-135.

Hinton, D. E., \& La Roche, M. J. (2013). Culturally appropriate CBT and anxiety disorders. In G. Simos \& S. G. Hofmann (Eds.),CBT for anxiety disorders: a practitioner book (pp 191224). Hoboken, NJ: Wiley-Blackwell.

Hinton, D. E., \& Jalal, B. (2014). Guidelines for the implementation of culturally sensitive cognitive behavioural therapy among refugees and in global contexts. Intervention, 12, 78-93.

Hinton, D. E., \& Lewis-Fernández, R. (2010). Idioms of distress among trauma survivors: Subtypes and clinical utility. Culture, Medicine, and Psychiatry, 34(2), 209-218.

Ho, H. C., Mui, M., Wan, A., Ng, Y. L., Stewart, S. M., Yew, C., ... Chan, S. S. (2016). Happy Family Kitchen II: A cluster randomized controlled trial of a community-based family intervention for enhancing family communication and well-being in Hong Kong. Frontiers in Psychology, 7, ArtID 6387.

International Monetary Fund. (2016). World economic outlook: subdued demand: symptoms and remedies. Retrieved from www.imf.org/external/pubs/ft/weo/2016/02/pdf/text.pdf

Jahoda, G. (2016). On the rise and decline of 'indigenous psychology'. Culture \& Psychology, 22(2), 169-181.

Joshanloo, M. (2014). Eastern conceptualizations of happiness: Fundamental differences with western views. Journal of Happiness Studies, 15(2), 475-493.

Kekic, L. (2008). The Economist Intelligence Unit's index of democracy. Retrieved from http://www.economist.com/ media/pdf/DEMOCRACY_INDEX_2007_v3.pdf

Kim, H., Doiron, K. M., Warren, M. A., \& Donaldson, S. I. (2018). The international landscape of positive psychology research: A systematic review. International Journal of Wellbeing, 8(1), 50-70.
Kirmayer, L. J. (2006). Beyond the 'new cross-cultural psychiatry': Cultural biology, discursive psychology and the ironies of globalization. Transcultural Psychiatry, 43(1), 126-144.

Kohn, R., Saxena, S., Levav, I., \& Saraceno, B. (2004). The treatment gap in mental health care. Bulletin of the World Health Organization, 82(11), 858-866.

Korn, E. L., \& Freidlin, B. (2012). Methodology for comparative effectiveness research: Potential and limitations. Journal of Clinical Oncology, 30(34), 4185-4187.

La Roche, M., \& Lustig, K. (2010). Cultural adaptations: Unpacking the meaning of culture. The Scientific Review of Mental Health Practice, 7, 26-30.

Lau, R. W., \& Cheng, S. T. (2011). Gratitude lessens death anxiety. European Journal of Ageing, 8(3), 169-175.

Layous, K., Chancellor, J., Lyubomirsky, S., Wang, L., \& Murali Dorais, P. (2011). Delivering happiness: Translating positive psychology intervention research for treating major and minor depressive disorders. The Journal of Alternative and Complementary Medicine, 17(8), 675-683.

Leu, J., Wang, J., \& Koo, K. (2011). Are positive emotions just as "positive" across cultures? Emotion, 11(4), 994.

Leventhal, K. S., DeMaria, L., Gillham, J., Andrew, G., Peabody, J., \& Leventhal, S. (2016). A psychosocial resilience curriculum provides the "missing piece" to boost adolescent physical health: A randomized controlled trial of Girls First in India. Social Science \& Medicine, 16, 37-46.

Leventhal, K. S., Gillham, J., DeMaria, L., Andrew, G., Peabody, J., \& Leventhal, S. (2015). Building psychosocial assets and wellbeing among adolescent girls: A randomized controlled trial. Journal of Adolescence, 45, 284-295.

Levine, M. (2011). The positive psychology of buddhism and yoga: Paths to a mature happiness. New York, NY: Taylor and Francis Group.

Luchetti, M. (2014). Global Health and the 10/90 gap. British Journal of Medical Practitioners, 7(4), a731.

Macaskill, A. (2016). Review of positive psychology applications in clinical medical populations. Healthcare, 4(66), 66.

Mascayano, F., Armijo, J. E., \& Yang, L. H. (2015). Addressing stigma relating to mental illness in low-and middle-income countries. Frontiers in Psychiatry, 6, 38.

Meffert, S. M., Neylan, T. C., Chambers, D. A., \& Verdeli, H. (2016). Novel implementation research designs for scaling up global mental health care: Overcoming translational challenges to address the world's leading cause of disability. International Journal of Mental Health Systems, 10(1), 19.

Mody, A. (2004). What is an emerging market?. Georgetown Journal of International Law, 35(4), 641-664.

Ong, A. D., Bergeman, C. S., Bisconti, T. L., \& Wallace, K. A. (2006). Psychological resilience, positive emotions, and successful adaptation to stress in later life. Journal of Personality and Social Psychology, 91, 730-749.

Rao, M. A., \& Donaldson, S. I. (2015). Expanding opportunities for diversity in positive psychology: An examination of gender, race, and ethnicity. Canadian Psychology/ Psychologie Canadienne, 56(3), 271-282.

Rashid, T. (2015). Positive psychotherapy: A strength-based approach. The Journal of Positive Psychology, 10(1), 25-40.

Rouholamini, M., Kalantarkousheh, S. M., \& Sharifi, E. (2016). Effectiveness of spiritual components training on life satisfaction of persian orphan adolescents. Journal of Religion and Health, 56(6), 1895-1902. 
Rye, M. S., Wade, N. G., Fleri, A. M., \& Kidwell, J. E. (2013). The role of religion and spirituality in positive psychology interventions. In K. I. Pargament (Ed), APA Handbook of Psychology, Religion, and Spirituality (pp. 481-508). Washington DC: American Psychological Association.

Saeedi, H., Nasab, S. H. M., Zadeh, A. M., \& Ebrahimi, H. A. (2015). The effectiveness of positive psychology interventions with Islamic approach on quality of life in females with multiple sclerosis. Biomedical and Pharmacology Journal, 8(2), 965-970.

Saraceno, B., Van Ommeren, M., Batniji, R., Cohen, A., Gureje, O., Mahoney, J., ... Underhill, C. (2007). Barriers to improvement of mental health services in low-income and middleincome countries. The Lancet, 370(9593), 1164-1174.

Schueller, S. M., Kashdan, T. B., \& Parks, A. C. (2014). Synthesizing positive psychological interventions: Suggestions for conducting and interpreting meta-analyses. International Journal of Wellbeing, 4(1), 91-98.

Schueller, S. M., \& Parks, A. C. (2014). The science of self-help. European Psychologist, 19(2), 145-155.

Schui, G., \& Krampen, G. (2010). Bibliometric analyses on the emergence and present growth of positive psychology. Applied Psychology, 2(1), 52-64.

Seligman, M. E. P., \& Csikszentmihalyi, M. (2000). Positive psychology: An introduction. American Psychologist, 55, 5-14.

Seligman, M. E. P., Steen, T. A., Park, N., \& Peterson, C. (2005). Positive psychology progress: Empirical validation of interventions. Tidsskrift for Norsk Psykologforening, 42(10), 874-884.

Selin, H., \& Davey, G. (2012). Happiness across cultures. Dordrecht, the Netherlands: Springer.

Shin, L. J., \& Lyubomirsky, S. (2017). Increasing well-being in independent and interdependent cultures. In M. Warren \& S. Donaldson (Eds), Scientific Advances in Positive Psychology (pp. 11-36). Santa Barbara, California: Praeger.

Sibbald, B., \& Roland, M. (1998). Understanding controlled trials. Why are randomised controlled trials important? British Medical Journal, 316(7126), 201.

Simmons, R., Fajans, P., \& Ghiron, L. (2007). Introduction. In R. Simmons, P. Fajans, \& L. Ghiron (eds), Scaling up health service delivery: From pilot innovations to policies and programmes (Vol. 2007, pp. vii-xvii.L). Geneva: WorldHealth Organization.

Sin, N. L., \& Lyubomirsky, S. (2009). Enhancing well-being and alleviating depressive symptoms with positive psychology interventions: A practice-friendly meta-analysis. Journal of Clinical Psychology, 65, 467-487.

Stewart, L. (2012). Commentary on cultural diversity across the pacific: The dominance of western theories, models, research and practice in psychology. Journal of Pacific Rim Psychology, 6(01), 27-31.
Sue, S. (1999). Science, ethnicity, and bias: Where have we gone wrong? American Psychologist, 54(12), 1070.

Sutipan, P., Intarakamhang, U., \& Macaskill, A. (2016). The impact of positive psychological interventions on wellbeing in healthy elderly people. Journal of Happiness Studies, 18(1), 269-291.

Talhelm, T., Haidt, J., Oishi, S., Zhang, X., Miao, F. F., \& Chen, S. (2015). Liberals think more analytically (more "WEIRD") than conservatives. Personality and Social Psychology Bulletin, 41 (2), 250-267.

Taylor, C. (1985). Philosophical papers. New York, NY: Cambridge University Press.

Teddlie, C., \& Tashakkori, A. (2011). Mixed methods research. In N. K. Denzin \& Y. S. Lincoln (Eds.), The Sage handbook of qualitative research (pp. 285-300). Thousand Oaks, CA: Sage.

Tugade, M. M., \& Fredrickson, B. L. (2004). Resilient individuals use positive emotions to bounce back from negative emotional experiences. Journal of Personality and Social Psychology, 86(2), 320.

United Nations Development Programme. (2015). Human Development Report. Retrieved from: hdr.undp.org/sites/ default/files/2015_human_development_report.pdf

Vazquez, C. (2013). Positive psychology and its enemies: A reply based on scientific evidence. Papeles Del Psicólogo, 34(2), 91-115.

Veenhoven, R. (2012). Does happiness differ across cultures?. In H. Selin \& G. Davey (Eds.), Happiness across cultures (pp. 451-472). Dordrecht, the Netherlands: Springer.

Vertiloa, V., \& Gibson, J. M. (2014). Influence of character strengths on mental health stigma. The Journal of Positive Psychology, 9(3), 266-275.

Vidyasagar, D. (2006). Global notes: The 10/90 gap disparities in global health research. Journal of Perinatology, 26(1), 55.

Walsh, S., Cassidy, M., \& Priebe, S. (2017). The application of positive psychotherapy in mental health care: A systematic review. Journal of Clinical Psychology, 73(6), 638651.

Walsh, Z. (2015). Buddhism and positive psychology. In D. A. Leeming (Ed.), Encyclopedia of Psychology and Religion (pp. 1-3). Berlin Heidelberg, Germany: Springer.

Wickramage, K. (2006). Sri Lanka'.s post-tsunami psychosocial playground: Lessons for future psychosocial programming and interventions following disasters. Intervention, 4, 163-168.

Woodworth, R. J., O'Brien-Malone, A., Diamond, M. R., \& Schuz, B. (2016). Happy Days: Positive psychology interventions effects on affect in an N-of-1 trial. International Journal of Clinical and Health Psychology, 16(1), 21-29. 